\title{
Creep of Structural Nuclear Composites
}

\author{
W.E. Windes \\ W.R. Lloyd
}

September 2005

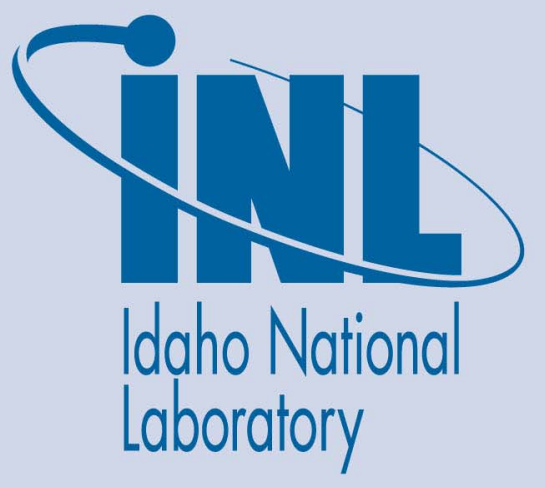

The INL is a U.S. Department of Energy National Laboratory operated by Battelle Energy Alliance 
INL/EXT-05-00747

\title{
Creep of Structural Nuclear Composites
}

\author{
W.E. Windes
}

W.R. Lloyd

September 2005

\section{Idaho National Laboratory \\ Idaho Falls, Idaho 83415}

Prepared for the

U.S. Department of Energy

Office of Nuclear Energy

Under DOE Idaho Operations Office

Contract DE-AC07-05ID14517 


\begin{abstract}
A research program has been established to investigate fiber reinforced ceramic composites to be used as control rod components within a Very High Temperature Reactor (VHTR) design. Two candidate systems have been identified, carbon fiber reinforced carbon $\left(\mathrm{C}_{\mathrm{f}} / \mathrm{C}\right)$ and silicon carbide fiber reinforced silicon carbide $\left(\mathrm{SiC}_{\mathrm{f}} / \mathrm{SiC}\right)$ composites. One of the primary degradation mechanisms anticipated for these core components is high temperature thermal and irradiation enhanced creep. As a consequence, high temperature test equipment, testing methodologies, and test samples for very high temperature (up to $1600^{\circ} \mathrm{C}$ ) tensile strength and long duration creep studies have been established. Actual testing of both tubular and flat, "dog-bone"-shaped tensile composite specimens will begin next year. Since there is no precedence for using ceramic composites within a nuclear reactor, ASTM standard test procedures are currently being established from these high temperature mechanical tests.
\end{abstract}




\section{SUMMARY}

Fiber reinforced ceramic composites are being considered for possible use as control rod cladding and guide tubes within a Very High Temperature Reactor (VHTR) design. A research program has been established to investigate these materials within the parameters of a VHTR core during service. Two candidate systems have been identified, carbon fiber reinforced carbon $\left(\mathrm{C}_{\mathrm{f}} / \mathrm{C}\right)$ and silicon carbide fiber reinforced silicon carbide $\left(\mathrm{SiC}_{\mathrm{f}} / \mathrm{SiC}\right)$ composites. Each material system exhibits high thermal stability, good mechanical strength, and relatively high fracture toughness.

Mechanical testing methodologies and capabilities for both candidate material systems are being established for temperatures up to $1600^{\circ} \mathrm{C}$. Test equipment, high temperature testing methodologies, VHTR reactor core conditions, and composite test sample design for high temperature tensile strength and long duration creep studies have been established. Since the control rods will be composed of tubular segments containing the high neutron crosssection material (i.e. $\mathrm{B}_{4} \mathrm{C}$ ), tubular test specimens were designed and fabricated for both composite types. In addition, small, flat tensile specimens were fabricated from composite plate materials in anticipation of the need for small, flat irradiation specimens that will actually fit within the reduced volume of a material test reactor core. Therefore, both tubular and flat plate tensile specimens were designed and fabricated for future mechanical testing. Actual testing of both tubular and flat, "dog-bone"-shaped tensile composite specimens will begin next year.

Specific attention was paid to the architectural fiber preform design as well as the materials used in construction of the composite test samples. For maximum irradiation stability and moderate composite strength, both composite types used a simple $\pm 45^{\circ}$ bi-axial braiding architecture. Much stronger threedimensional weaving was considered unnecessary for these moderately low stressed components. A much more important consideration was material selection, which resulted in significantly higher irradiation stability for both composite types. SiC composites used Hi-Nicalon Type-S fiber preforms with chemical vapor infiltration while the $\mathrm{C}_{\mathrm{f}} / \mathrm{C}$ composites used pitch fiber-pitch matrix composites with liquid infiltration techniques. These preform materials have been demonstrated to have superior irradiation stability to other $\mathrm{SiC}$ and carbon-based material systems.

Currently, there is no precedent for using ceramic composites within a nuclear reactor. Consequently, no ASTM standards or ASME code cases exist for using ceramic composite components in a nuclear core. This research program will use the test procedures and methodology established during these studies to create standardized mechanical and environmental test procedures for use in validating a structural ceramic composite for use in a nuclear reactor system. ASTM (or equivalent) standards are being created for the composite architectures used and the high temperature test methods developed (both for tensile strength and creep tests) for ceramic composites. In addition, ASTM round-robin test methods will be used to validate that these test standards are truly international standards that can be applicable to all reactor designs. 


\section{CONTENTS}

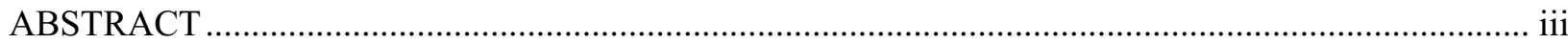

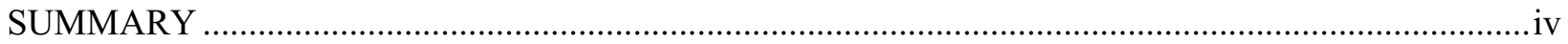

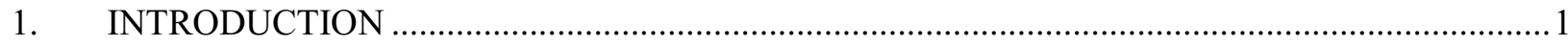

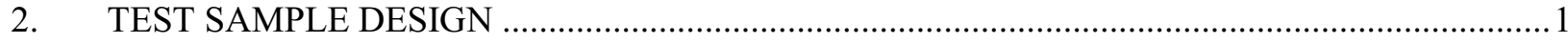

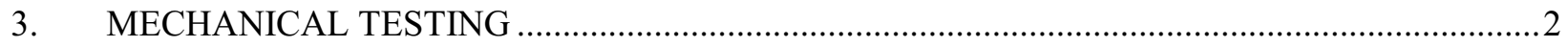

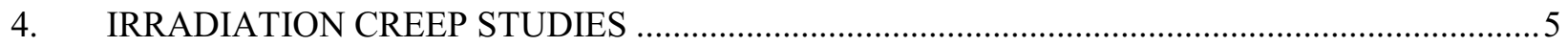

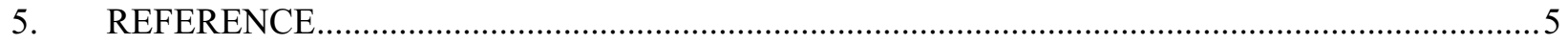

\section{FIGURES}

1. Schematic illustrations of a) environmental chamber surrounding sample and grip assembly b) high temperature grips and extensometers with sample, and c) grip assembly inside cut-away

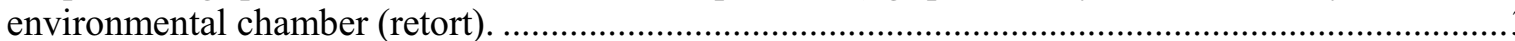

2. Typical environmental chamber housing required electronics, mechanical grips, and extensometers inside an Inconel chamber capable of withstanding test temperatures of $1000^{\circ} \mathrm{C}$........................... 3

3. High temperature grip design for passive loading of tubular test specimen. ........................................5 


\section{Creep of Structural Nuclear Composites}

\section{INTRODUCTION}

Extensive thermo-mechanical testing will be required to determine whether $\mathrm{SiC}_{\mathrm{f}} / \mathrm{SiC}$ or $\mathrm{C}_{\mathrm{f}} / \mathrm{C}$ ceramic composites are truly viable in a control rod cladding application. Since the temperatures within a VHTR core are anticipated to be extreme $\left(\sim 1600^{\circ} \mathrm{C}\right)$ thermal stability, or creep resistance, is recognized as a primary degradation mechanism over the lifetime of the reactor (up to 60 years). In addition, core components are expected to receive the largest flux levels with a corresponding total dose of $30 \mathrm{dpa}$ for these lifetime components. This requires that an extensive thermal and irradiation creep program be conducted upon these composite systems to determine the structural stability over the reactor lifetime.

High temperature creep studies will be required to determine a baseline creep response of the tubular geometry components. Mechanical tensile tests conducted at expected normal reactor temperatures $\left(\sim 1100^{\circ} \mathrm{C}\right)$ and anticipated off-normal temperatures $\left(1600^{\circ} \mathrm{C}\right)$ at nominal stress levels $(\sim 10$ $\mathrm{MPa})$ will provide the baseline creep response for these material systems. Once the non-irradiated creep response has been established the enhanced creep effects resulting from neutron irradiation will be determined by irradiating composite test samples. Irradiation doses comparable to a lifetime exposure ( $\sim 30 \mathrm{dpa})$ will be used to quantify the creep response of these composite components.

Traditionally, it is standard practice to use small, representative test samples in place of full-size components. However, a real problem exists for scale-up of composite materials. Unlike monolithic materials these are composites engineered from two distinct materials using complicated infiltration techniques to provide full density and maximum mechanical properties. The material properties may be significantly affected when the component geometry or size is changed. This is a major consideration since small sample sizes and more suitable geometries are required for test samples especially for irradiated sample studies where the material must be placed within the limited space of a reactor. It must be demonstrated that the smaller test samples adequately represent the true response of larger composite tubes used for control rod applications.

To accomplish this, standardized mechanical tests will be developed from these studies to provide the necessary data required for codification of these materials for use in a nuclear environment. This data, even though it is recognized as preliminary only, will most likely be used in support of a code case for use of composite materials as control rod tubes.

\section{TEST SAMPLE DESIGN}

Both non-irradiated and irradiated high temperature mechanical testing must be performed to ascertain the response for these two ceramic composite systems. While standardized sample test sizes and tubular geometry can be used for non-irradiated baseline testing irradiated studies will require miniaturized samples that can be easily accommodated within the restricted space of a reactor. To fit into any nuclear reactor, test samples much smaller than the actual control rod diameters ( 100 -mm dia.) will be required. In addition, to further reduce the test sample volume and provide a larger number of irradiated samples, flat, "dog-bone"-shaped tensile specimens are considered to be an optimal geometry for test specimens. However, before these smaller, flat tensile specimens can be utilized it needs to be established that they are truly representative of large tubes, which would be used for the control rods.

Two different test programs are required to establish that small, flat test specimen are representative of the mechanical response for large, cylindrical composite tubes; a size effect study and a 
geometry effect study. These studies will be performed on non-irradiated test specimens with similar fiber preform architectures and infiltration techniques.

Geometry effects: Small tubular specimens approximately 125-mm long x 10-mm diameter have been fabricated along with large $254-\mathrm{mm} \times 76-\mathrm{mm}$ flat plates for future testing. ${ }^{1}$ Flat tensile specimens with similar outer dimensions as the tubular specimens will be machined from the flat plate stock. Both flat plate and tubular specimens will be compared and analyzed in "head-to-head" mechanical tests.

Size effects: Once the geometry effects have been accounted for, the effects resulting from sample size on the mechanical response will be investigated. The size effects study will be conducted with tubular samples only. Flat tensile specimens will not be used. A series of variable sized tubular samples will be fabricated for tensile testing. Sizes will range from $10-\mathrm{mm}$ dia. $-50-\mathrm{mm}$ dia. and may include a full-size (i.e. 100-mm) series of test specimens if deemed appropriate based upon the results from the smaller diameter testing.

\section{MECHANICAL TESTING}

A round robin testing program has been initiated for all labs (ORNL, INL, PNNL, and University of Bordeaux-France) with the appropriate number of tubular and flat plate specimens. Once the sample matrix has been established the participating laboratories will mechanically test the samples using similar testing methods. The results will be fed back to the appropriate ASTM subcommittee (or working group) and analyzed. Experts from all labs must work within ASTM guidelines and methods to produce a defensible test matrix and testing procedures for ceramic composite tubes.

Initial tensile strength tests will be required to determine failure response, high temperature "yield strength" or tensile matrix-cracking stress, and geometry effects for both tubular and flat plate specimens. The tests will be conducted over a range of temperatures $\left(\mathrm{RT}-1600^{\circ} \mathrm{C}\right)$ to envelope the anticipated operating conditions within a VHTR. The high temperature failure response and matrix-cracking stresses will be used to determine the optimal stress loads for long-term creep studies.

Room-temperature studies: Room temperature tensile tests of both tubular and flat plate specimens are primarily designed to investigate the geometry effects study. The quantitative geometry effects between the tubular and flat plate specimens will be determined using a series of head-to-head comparison tests between the flat "dog-bone" and tubular tensile specimens. These tests will be conducted both at the USA national laboratories and with our French collaborators as part of the international test standards development for structural ceramics in nuclear applications.

In addition, the tensile strength results will also provide a comparative study to previous work in these composite systems for the fusion materials program. The fusion materials program used specimens fabricated from different fiber preform architectures and different geometries (i.e. flat, loom-woven plate material). A comparison of the new tensile strength results to the previous results used in the fusion work will illustrate the fabricability of the new tubular geometry components. Any dramatic changes from the expected strength levels would affect the viability of these composites.

To date, new ceramic load grips designed for both tubular and flat specimens have been designed (see later section) as well as an ASTM test matrix for both geometries. Tensile tests and comparison studies on both composite types will begin next year.

High temperature studies: Similar to the room temperature studies, both the Hi Nicalon Type-S tubular and flat tensile specimens will be tested. The tests will be conducted from $900^{\circ} \mathrm{C}$ to $1600^{\circ} \mathrm{C}$ over 
a range of times to provide a non-irradiated baseline of tensile strength, matrix-cracking stress, and creep data for these ceramic composite systems.

Both sample geometries will be tested within high temperature load frames using vertical clamshell heaters and a static load. However, due to the anticipated service in the VHTR, the test frames will necessarily be outfitted with an environmental chamber allowing the samples to be tested at temperature in a He atmosphere, Figures 1 and 2.
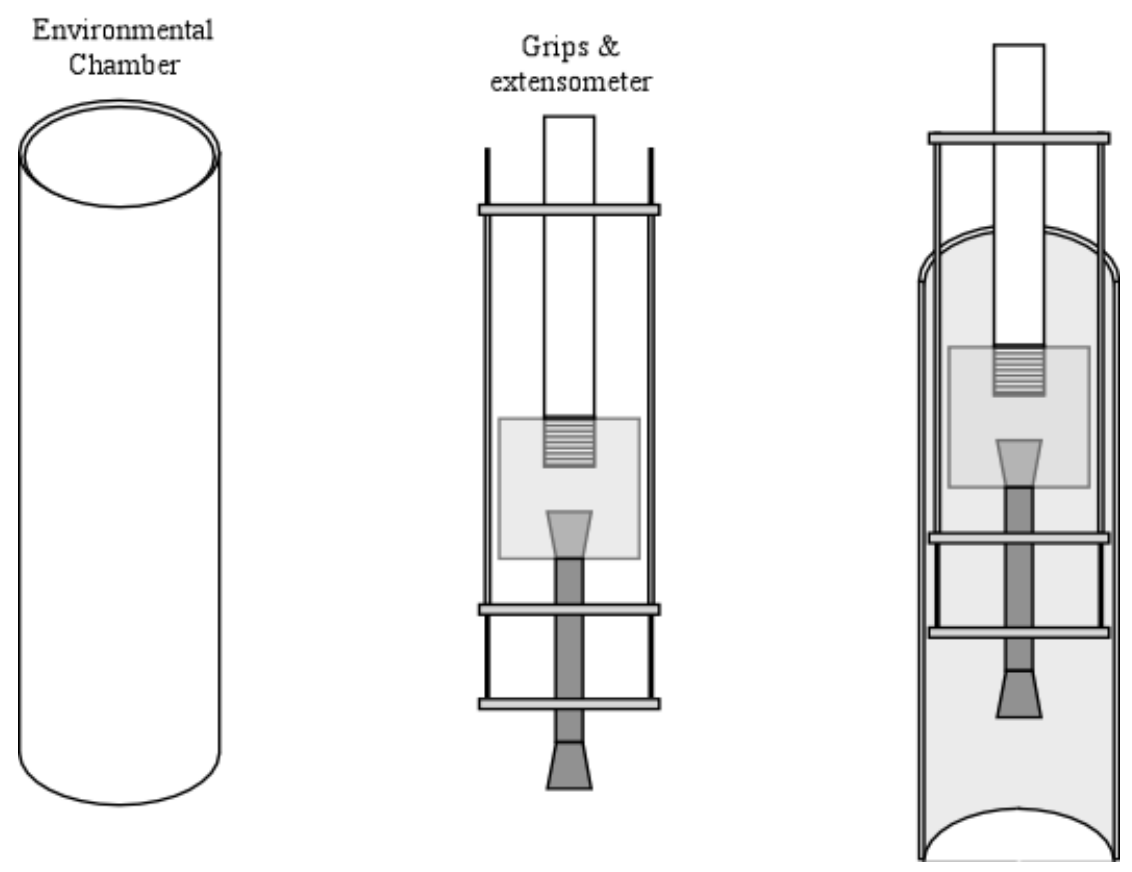

Figure 1. Schematic illustrations of a) environmental chamber surrounding sample and grip assembly b) high temperature grips and extensometers with sample, and c) grip assembly inside cut-away environmental chamber (retort).

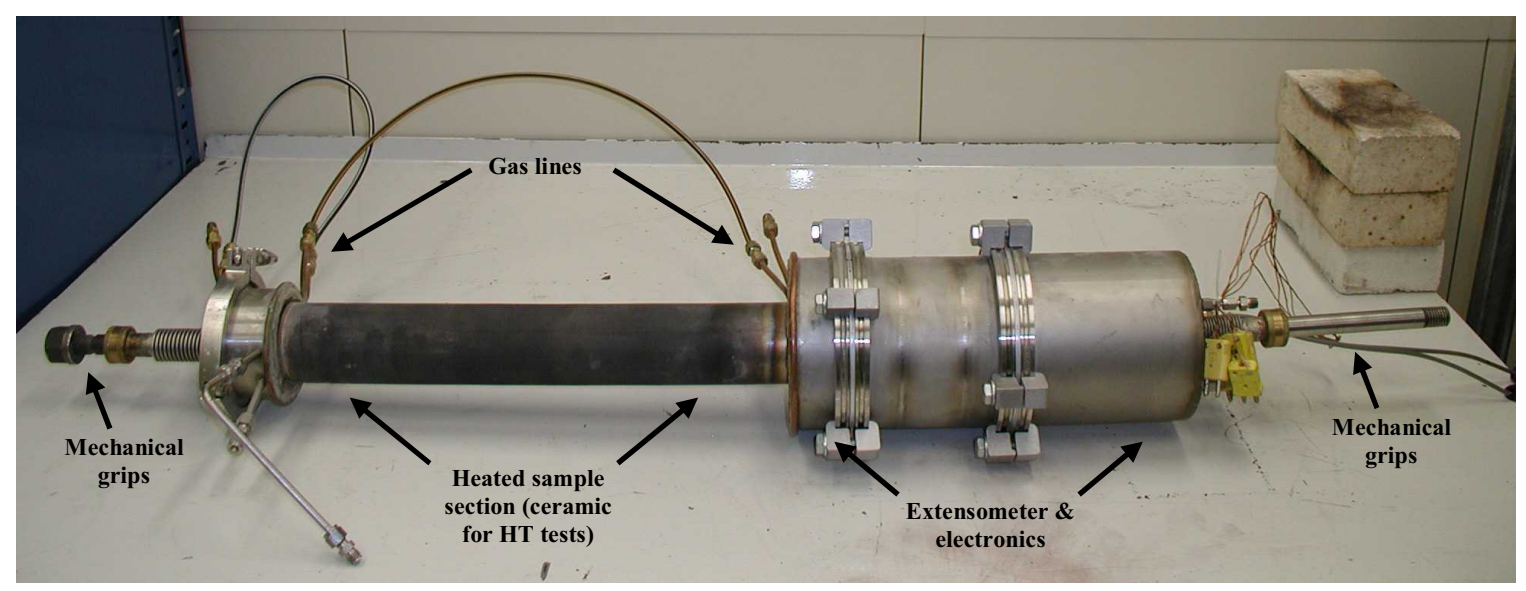

Figure 2. Typical environmental chamber housing required electronics, mechanical grips, and extensometers inside an Inconel chamber capable of withstanding test temperatures of $1000^{\circ} \mathrm{C}$.

Currently, load frames capable of very high temperature operation $\left(<1700^{\circ} \mathrm{C}\right)$, using compatible environmental chambers, and appropriate controllers have been modified in support of the high 
temperature tests. The new furnaces will be capable of sustained temperatures in excess of $1600^{\circ} \mathrm{C}$ to envelope the anticipated operating temperatures of the control rods while the ceramic retort environmental chambers will provide the necessary environmental conditions. The modifications include the following:

- Two resistive heating element (Super Kanthal, $\mathrm{MoSi}_{2}$ ) furnaces with nominal $100 \mathrm{~mm}$ diameter by $200 \mathrm{~mm}$ long heated zones, capable of sustained temperatures above $1600^{\circ} \mathrm{C}$ have been obtained from Advanced Testing Systems (ATS), along with independent power supplies.

- Two environmental retorts have been purchased and received from ATS. These retorts will allow atmospheric control surrounding specimens within the furnaces at temperatures up to $1600^{\circ} \mathrm{C}$. The inside diameter of the hot section (approximately 150-mm long) of the retorts is nominally $92 \mathrm{~mm}$.

- The central tubes of the retorts (ceramic environmental chambers) are 100-mm diameter x 775-mm long high-purity alumina tubes with precision ground end sections. These tubes have been ordered from McDanel Advanced Ceramics in Pennsylvania. They are due to arrive sometime about November 1, 2005.

- The two ATS creep frames have had their test sections extended by $300 \mathrm{~mm}$ to accommodate the new retorts and furnaces. The vertical members of the frame were sectioned and $300 \mathrm{~mm}$ lengths of steel channel were inserted and welded into place. These modifications are completed.

- Control of both the creep loading frames and furnaces, as well as continuous collection of test data is accomplished through a new control system (WinCCS II) purchased from ATS. The control system was delivered along with the furnaces and retorts.

- Frame interface boards and related wiring modifications to the two frames are currently underway. A request has been submitted to facility electricians and pipe fitters to relocate or provide new (as appropriate) electrical power for the test frames and control system, and the furnaces, and to provide plant water cooling supply and drain lines for the retorts.

The high purity ceramic alumina environmental chambers will be required for the very high test temperatures (up to $1600^{\circ} \mathrm{C}$ ) and long duration of the creep tests. The relatively small sample sizes for both the tubular and the flat plate specimens will be accommodated within the limited volume of the environmental chambers, see Figure 1. A high purity helium gas environment will be used within the chambers to simulate the VHTR reactor environment. High temperature tests and comparison studies on both composite types will begin next year.

High temperature grip and extensometer design: Appropriate high temperature grips, extensometers, and insulation requirements inside the environmental chamber were also addressed. At the expected high test temperatures actively loaded grips will not be possible for long-term creep studies (i.e. mechanically tightened grips will creep and relax inside the environmental chamber). Therefore, a shoulder-mounted gripping system was designed to allow passive gripping for high temperature testing. This required the tensile specimens to have a tapered end, or shoulder, fabricated on each end of the specimen.

High temperature grips capable of being used for both tubular and flat tensile specimens are being designed and fabricated. These are passive grips that use the flared ends of the test samples to load the specimens in tension, as opposed to active grips which are spring loaded and may lose their gripping force if exposed to high temperatures over long periods of time, Figure 3. 

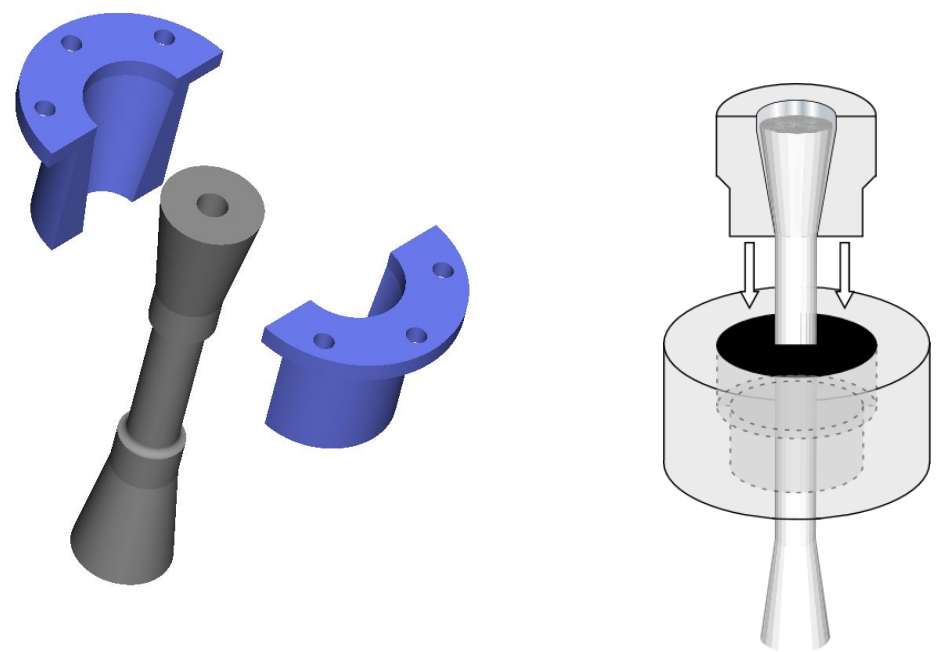

Figure 3. High temperature grip design for passive loading of tubular test specimen.

The grips will be made from either graphite or silicon carbide for maximum thermal stability and strength. Over-sized components will reduce creep induced failures for long-duration tests.

\section{IRRADIATION CREEP STUDIES}

As stated previously, the primary degradation mechanism identified for composite control rod components is irradiation creep. Preliminary discussions focusing on irradiation sample dimensions, loading methods, and the design of an irradiation canister for insertion into a reactor have been conducted.

Irradiation samples will necessarily need to be small and compact to minimize volume within the reactor core. Using previous experience and sample designs for creep studies of metals and monolithic materials a general sample size approximately $50-\mathrm{mm}$ long and $12-\mathrm{mm}$ wide (at the ends) has been determined. No detailed dimensions for the samples have been finalized to date. A final design for load grips or the irradiation canister has also not been determined. Detailed discussions of the sample dimensions and canister design will be initiated next year.

\section{REFERENCE}

1. Yutai Katoh, L. L. Snead, E. Lara-Curzio, W.E. Windes, and R. J. Shinavski, "Summary of SiC Tube Architecture and Fabrication," ORNL-GEN4/LTR-05-07, 2005, August 30, 2005. 